\title{
PHYSICO-MECHANICAL PROPERTIES OF WOOD AND NON- WOOD PLASTER OF PARIS BONDED COMPOSITE CEILING BOARDS
}

\author{
TEMIDAYO EMMANUEL OMONIYI*1, KAYODE AYODELE AJOBIEWE ${ }^{1}$ \\ ${ }^{1}$ Department of Wood Products Engineering, University of Ibadan, Ibadan, Nigeria
}

\begin{abstract}
The effects of wood and non-wood fibres reinforcement on the properties of Plaster of Paris were evaluated. The woody and non woody residues were varied in 10, 20, 30, 40, and $50 \%$ of the whole mix while the Plaster of Paris used was in the ratio 100 (control), 90, 80, 70, 60 , and $50 \%$. The mean density of the composite produced is $3250 \mathrm{~kg} / \mathrm{m}^{3}$. The mean thickness swelling and water absorption after 2 and 24 hours were $0.84 \%$ and $0.88 \%$, and $13.8 \%$ and $16.2 \%$ respectively. The MOR and MOE increased with increase in fibre content hence the composite is suitable for indoor applications.
\end{abstract}

Keywords: wood composites, physico-mechanical, fibre reinforcement, plaster of Paris, ceiling board.

\section{INTRODUCTION}

Reinforced Plaster of Paris (POP) Composite ceiling boards, is a new decorative and finishing material that is gaining increasing importance and usage. Plaster of Paris or gypsum is a very soft sulphate mineral of chemical formulae $\mathrm{CaSO}_{4} 2 \mathrm{H}_{2} \mathrm{O}$ which present itself often as monoclinic, massive, flat or elongated and generally prismatic crystals with its color ranging from colorless to white [1]. In recent years, asbestos materials for making ceiling boards have been banned in many advanced countries due to its carcinogenic nature, with agencies in construction industries having identified its real and potential adverse effect on humans [2]. As a result, POP is gaining stand among builders and house owners who are practically interested in the alternative it provides to asbestos. Locally sourced building materials which would facilitate sustainable development remain underdeveloped to a socially and economically acceptable level, owing to the low level of development of the economy [3]. It was reported by [4] that, composite is designed to take advantage of the desirable characteristics of constituent materials by choosing an appropriate combination of matrix and reinforcement material, thus producing a new material that meets the exact requirements of a particular application.

Among the natural fibres that have been used for reinforcement in composite boards include; bagasse fibre [5], Rattan [6], oil palm [7], sisal fibres [8], coconut coir [9], pineapple leaves [10] etc. Each of the researchers reported significant improvement to the properties of the composites formed. However, this may depend on the percentage of the natural fibres present in the matrix as well as the type of pre-treatment performed on the fibre before mixing. These natural fibres have been used mostly with cement as the binder and some of them can serve as potential reinforcement materials for POP in order to make it affordable and can in some ways increase the mechanical properties.

Yarn, a natural non-woody fibre is a long continuous length of interlocked fibres suitable for use in the production of textiles, sewing, crocheting, knitting weaving, embroidery, and roe making, while rattan, also one of the natural

\footnotetext{
* Corresponding author, email: temidayoomoniyi@gmail.com

(c) 2020 Alma Mater Publishing House
} 
non-woody fibres, is a stick made from the stem of the rattan palms. Rattan canes are numbered among the important commercial non-timber forest products employed in furniture industry in the tropics, however over $30 \%$ of rattan harvested at any time particular for furniture manufacture are wastes [6]. Alzibia zygia is a deciduous tree nine to thirty meters tall with a spreading crown and a graceful architectural form and its bole tall and clear, around $240 \mathrm{~cm}$ in diameter. It has a dark grey and smooth surface [11]. These materials could be experimented as reinforcement to improve the properties of Plaster of Paris in order to produce a durable, affordable, and environmentally friendly (non-carcinogenic substances) material suitable structurally as ceiling boards. The objective of this study, therefore, was to investigate the effects of some woody and non-woody natural fibres contents on the strength and sorption properties of POP.

\section{METHODOLOGY}

\subsection{Materials Collection}

Saw dust of Alzibia zygia collected from Bodija plank market in Ibadan was graded and sieved to remove impurities, then oven dried to around $101{ }^{\circ} \mathrm{C}$ to reduce the moisture content of the fibre. Rattan, yarn fibres and Plaster of Paris were purchased from a retail outlet also in Ibadan.

\subsection{Procedure}

The fibrous materials were sun dried then hammer milled and weighed accordingly. The fibre-POP composites were produced by manual dry-mixing of the Alzibia zygia fibres and the POP in a plastic bowl at different fibre contents $(0 \%, 10 \%, 20 \%, 30 \%, 40 \%$, and $50 \%$ respectively). This continued until a homogeneous mixture was formed. An estimated volume of water from preliminary was added to the contents and mixed continually until a desirable level of uniformity was achieved. The wet mixture was poured into a unit of $500 \mathrm{~mm}$ by $300 \mathrm{~mm}$ by $6 \mathrm{~mm}$ plastic sheet placed in a mould on a table vibrator as shown in Figure 1. The content was spread over the mould until it properly covered the whole area. The table was then vibrated for 60 seconds. The specimen was left to moist cure for 24 hours and later left in water for 28 days, from preliminary, for proper curing. Three replicates of the samples were produced for each of the specimen designation presented in Table 1 . The process was repeated for rattan and yarn fibre-POP composites production as presented in Table 2 and 3 respectively. The produced composite materials were then subjected to test to investigate their physical and mechanical properties.

Table 1. Plaster of Paris (POP) and Alzibia zygia (Ayunre).

\begin{tabular}{cccc}
\hline Specimens & POP $(\%)$ & Wood fibre $(\%)$ & Samples produced \\
\hline PWF1 & 100 & 0 & 3 \\
PWF2 & 90 & 10 & 3 \\
PWF3 & 80 & 20 & 3 \\
PWF4 & 70 & 30 & 3 \\
PWF5 & 60 & 40 & 3 \\
PWF6 & 50 & 50 & 3 \\
\hline
\end{tabular}

PWF = Plaster Of Paris $(P O P)+$ wood fibre

Table 2. Plaster of Paris and Rattan fibre.

\begin{tabular}{cccc}
\hline Specimen & POP $(\%)$ & Rattan fibre $(\%)$ & Samples produced \\
\hline PRF1 & 100 & 0 & 3 \\
PRF2 & 90 & 10 & 3 \\
PRF3 & 80 & 20 & 3 \\
PRF4 & 70 & 30 & 3 \\
PRF5 & 60 & 40 & 3 \\
PRF6 & 50 & 50 & 3 \\
\hline
\end{tabular}

PRF $=$ Plaster of Paris $(P O P)+$ rattan fibre 
Table 3. Plaster of Paris and Yarn fibre.

\begin{tabular}{cccc}
\hline Samples & POP $(\%)$ & Yarn fibre $(\%)$ & Samples produced \\
\hline PYF1 & 100 & 0 & 3 \\
PYF2 & 90 & 10 & 3 \\
PYF3 & 80 & 20 & 3 \\
PYF4 & 70 & 30 & 3 \\
PYF5 & 60 & 40 & 3 \\
PYF6 & 50 & 50 & 3 \\
\hline
\end{tabular}

PYF $=$ Plaster of Paris $(P O P)+$ Yarn fibre

\subsection{Composite Property Tests}

The following tests were carried out on the specimens.

Density: After curing, the samples were weighed on a digital weighing scale and their corresponding weight in kilograms was recorded. The density of the materials was calculated from equation (1) as given by [1]:

$$
\partial_{c}=\frac{W}{V}
$$

where $\partial_{c}$ is the density in $\left(\mathrm{Kg} / \mathrm{m}^{3}\right)$ of the composite produced, $\mathrm{w}$ is the weight of the composite produced and $\mathrm{v}$ is the volume of the produced composite.

Specific gravity (SG): The specific gravity was calculated using equation (2) as given by [1]:

$$
S G=\partial c / \partial w
$$

where $S G$ is the specific gravity of samples, $\partial c$ is the density of composites produced $\left(\mathrm{kg} / \mathrm{m}^{3}\right)$ and $\partial w$ is the density of water in $\left(1000 \mathrm{~kg} / \mathrm{m}^{3}\right)$.

Water Absorption and Thickness swelling: The specimen from each specimen were submerged horizontally under $50 \mathrm{~mm}$ of distilled water maintained at a room temperature of about $27{ }^{\circ} \mathrm{C}$. The amount of water absorbed after 2 hours and 24 hours were recorded. The $\%$ water absorption and $\%$ thickness swelling were calculated using equation (2) and equation (3) respectively:

$$
\% \text { water absorption }=\frac{\mathrm{w}_{2}-\mathrm{w}_{1}}{\mathrm{w}_{1}} \times 100 \%
$$

where $\mathrm{w}_{1}$ and $\mathrm{w}_{2}$ is the initial and final weight before and after soaking respectively:

$$
\% \text { Thickness swelling }=\frac{t_{2}-t_{1}}{t_{1}} \times 100 \%
$$

where $t_{1}$ and $t_{2}$ is the initial and final thickness before and after soaking.

Modulus of Rupture (MOR): This was conducted to approximate the bending strength of the produced composite materials. The samples were tested using the OKH-600 digital display universal test machine (UTM) of the Department of Agricultural and Environmental Engineering, University of Ibadan in accordance with [12]. The test was carried out on the sample specimens shown in Figure 2.

\section{Modulus of Elasticity (MOE):}

The MOE of the samples was determined using the OKH-600 digital display Universal Testing Machine in accordance with [12]. The test was carried out on the samples displayed in Figure 2. 


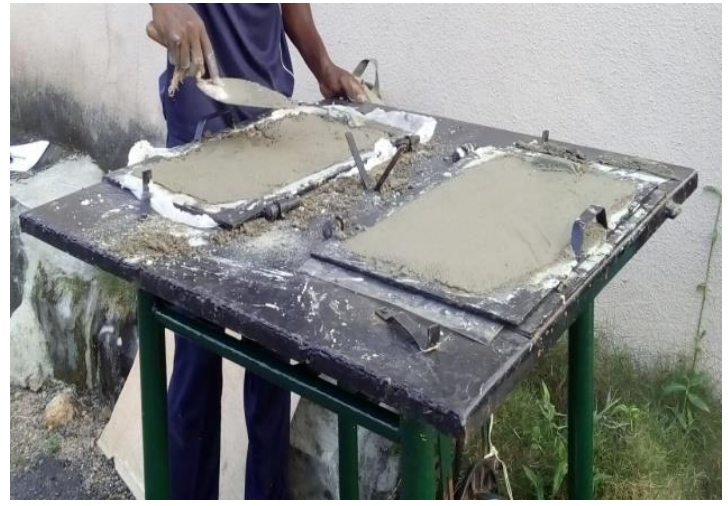

Fig. 1. Producing samples with Vibrating table.

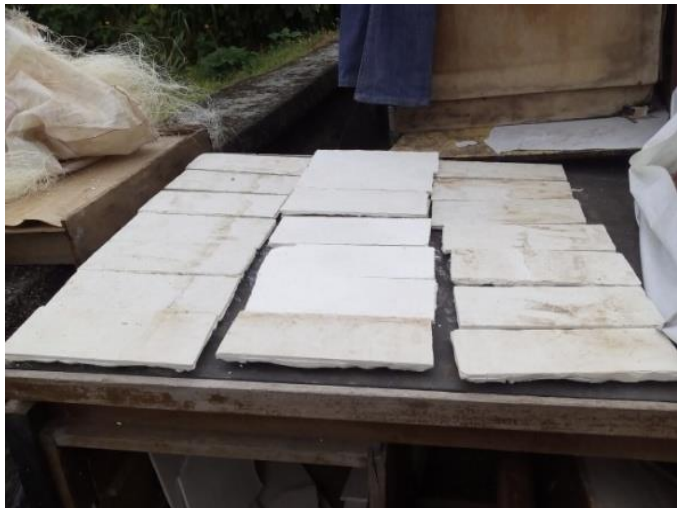

Fig. 2. Samples of the fibre composites.

\section{RESULTS AND DISCUSSIONS}

\subsection{Density and specific gravity}

Figure 2 shows the produced composite materials. Table 4 shows the densities and specific gravity of the material produced. The densities vary from $3200 \mathrm{~kg} / \mathrm{m}^{3}$ to $3900 \mathrm{~kg} / \mathrm{m}^{3}$ (wood fibre), $2700 \mathrm{~kg} / \mathrm{m}^{3}$ to $4500 \mathrm{~kg} / \mathrm{m}^{3}$ (rattan fibre), $2000 \mathrm{~kg} / \mathrm{m}^{3}$ to $4500 \mathrm{~kg} / \mathrm{m}^{3}$ (yarn fibre) and $4700 \mathrm{~kg} / \mathrm{m}^{3}$ (POP only). Samples produced with POP alone have higher densities compared to samples reinforced with fibre this may be due to the lighter weight of the fibres. Increase in the fibre content of the composite produced decreases the density and specific gravity of the material which is in accordance with the report on wood composite by [6].

Table 4. Density and specific gravity of composites.

\begin{tabular}{|c|c|c|c|c|c|c|}
\hline $\begin{array}{c}\text { Sample } \\
\text { POP/fibre }\end{array}$ & $\begin{array}{c}{ }^{3} \partial \mathrm{PWF} \\
\left(\mathrm{kg} / \mathrm{m}^{3}\right)\end{array}$ & $\begin{array}{c}{ }^{3} \partial_{\mathrm{PRF}} \\
\left(\mathrm{kg} / \mathrm{m}^{3}\right)\end{array}$ & $\begin{array}{c}{ }^{3} \partial \mathrm{PYF} \\
\left(\mathrm{kg} / \mathrm{m}^{3}\right)\end{array}$ & SGPWF & SGPRF & SGPYF \\
\hline $100 / 0$ & 4700 & 4700 & 4700 & 4.7 & 4.7 & 4.7 \\
\hline 90/10 & 3900 & 4500 & 4500 & 3.9 & 4.5 & 4.5 \\
\hline $80 / 20$ & 3500 & 4000 & 3500 & 3.5 & 4 & 3.5 \\
\hline $70 / 30$ & 3480 & 3000 & 3200 & 3.48 & 3 & 3.2 \\
\hline $60 / 40$ & 3320 & 3100 & 2700 & 3.32 & 3.1 & 2.7 \\
\hline $50 / 50$ & 3200 & 2700 & 2000 & 3.2 & 2.7 & 2 \\
\hline
\end{tabular}

$\overline{\mathrm{POP} / \text { fibre }}=$ percentage of $\mathrm{POP} /$ percentage of fibre, $\partial_{\mathrm{PWF}}=$ density of POP and wood fibre composite, $\partial_{\mathrm{PRF}}=$ density of $\mathrm{POP}$ and rattan fibre composites, $\partial_{\mathrm{PYF}}=$ density of POP and Yarn fibre composites, ${ }^{3}$ Average of three values

\subsection{Thickness Swelling and water absorption (WA)}

Table 5 shows the water absorption percentage of the composite materials. Cumulatively, the higher the fibre content in the composite, the higher the water absorption, which may be due to the hydrophilic nature of the wood and the other fibres. The behaviour of the produced composites was similarly reported by [13], that the presence of hydroxyl groups inside the cellulose and hemi celluloses attract the water molecules and form hydrogen bonding. Moreover, due to the porous structure of wood fibres, the composites with higher wood content absorb more water which penetrates into the pores according to the principle of capillary flow. The yarn fibre absorbed the lowest amount of water content. The WA property also increased with the time of immersion as expected, and that explains the disparity in value after $2 \mathrm{hrs}$ and $24 \mathrm{hrs}$ immersion.

Table 6 shows the results of the thickness swelling test. Generally, the change in thickness of the produced composites is very minimal after 2 and 24 hours. The yarn fibre has the best performance under the thickness swelling test. As reported by [2], increase in the fibre ratio of the composites increases the thickness swelling after water immersion. 
Table 5. Water absorption (\%) of composites produced.

\begin{tabular}{|c|c|c|c|c|c|c|}
\hline $\begin{array}{c}\text { Sample } \\
\text { POP/Fibre }\end{array}$ & $\begin{array}{c}{ }^{3} \text { WAPWF (\%) } \\
\text { (2hrs) }\end{array}$ & $\begin{array}{c}{ }^{3} \text { WAPWF }(\%) \\
(24 h r s)\end{array}$ & $\begin{array}{c}{ }^{3} \text { WAPRF }(\%) \\
(2 \mathrm{hrs})\end{array}$ & $\begin{array}{c}{ }^{3} \text { WAPRF (\%) } \\
\text { (24hrs) }\end{array}$ & $\begin{array}{c}{ }^{3} \text { WAPYF (\%) } \\
\text { (2hrs) }\end{array}$ & $\begin{array}{c}{ }^{3} \text { WAPYF }(\%) \\
\text { (24hrs) }\end{array}$ \\
\hline $100 / 0$ & 11.53 & 15.2 & 11.55 & 15.23 & 11.63 & 11.24 \\
\hline $90 / 10$ & 14.87 & 15.75 & 13.98 & 14.24 & 12.32 & 12.94 \\
\hline $80 / 20$ & 15.06 & 16.98 & 14.28 & 14.93 & 12.72 & 13.19 \\
\hline $70 / 30$ & 15.47 & 18.78 & 14.72 & 15.34 & 13.01 & 13.89 \\
\hline $60 / 40$ & 15.90 & 19.22 & 14.84 & 15.45 & 13.59 & 14.14 \\
\hline $50 / 50$ & 15.98 & 20.02 & 15.77 & 16.32 & 14.34 & 15.21 \\
\hline
\end{tabular}

$\mathrm{WA}_{\mathrm{PWF}}=$ Water Absorption for POP-wood fibre composites, WAPRF $=$ Water Absorption for POP-rattan fibre composites, WAPYF $=$ Water Absorption for POP-Yarn fibre composites, ${ }^{3}$ Average of three values.

Table 6. Thickness swelling (\%) of composites.

\begin{tabular}{|c|c|c|c|c|c|c|}
\hline $\begin{array}{c}\text { Sample } \\
\text { POP/Fibre }\end{array}$ & $\begin{array}{c}{ }^{3} \text { TSPWF }(\%) \\
\text { (2hrs) }\end{array}$ & $\begin{array}{c}{ }^{3} \text { TSPWF }(\%) \\
\text { (24hrs) }\end{array}$ & $\begin{array}{c}{ }^{3} \text { TSPRF }(\%) \\
\text { (2hrs) }\end{array}$ & $\begin{array}{c}{ }^{3} \text { TSPRF }(\%) \\
\text { (24hrs) }\end{array}$ & $\begin{array}{c}{ }^{3} \text { TSPYF }(\%) \\
\text { (2hrs) }\end{array}$ & $\begin{array}{c}{ }^{3} \text { TSPYF (\%) } \\
\text { (24hrs) }\end{array}$ \\
\hline $100 / 0$ & 0.39 & 0.59 & 0.39 & 0.59 & 0.39 & 0.59 \\
\hline $90 / 10$ & 0.58 & 0.78 & 0.48 & 0.69 & 0.40 & 0.58 \\
\hline $80 / 20$ & 0.77 & 0.88 & 0.51 & 0.78 & 0.58 & 0.59 \\
\hline $70 / 30$ & 0.96 & 1.18 & 0.76 & 0.98 & 0.58 & 0.67 \\
\hline $60 / 40$ & 1.28 & 1.57 & 0.98 & 1.13 & 0.77 & 0.98 \\
\hline $50 / 50$ & 1.35 & 1.96 & 1.17 & 1.23 & 0.79 & 0.99 \\
\hline
\end{tabular}

$\mathrm{TS}_{\mathrm{PWF}}=$ thickness swelling of POP-wood fibre composites, $\mathrm{TS}_{\mathrm{PRF}}=$ thickness swelling of POP-Rattan fibre composites, $\mathrm{TS}_{\mathrm{PYF}}=$ thickness swelling of POP-Yarn fibre composites, ${ }^{3}$ Average of three values

\subsection{Modulus of elasticity (MOE) and modulus of rupture (MOR)}

The strength properties of the composites were shown in Table 7. The introduction of fibre tends to increase the Modulus of Elasticity of the composites as the primary objective of fibres as filler is to increase the stiffness of composites. The results tally with the report of [14], in which the tensile and flexural strength slightly increased with increasing wood fibre content of a Wood Plastic Composites. The rattan fibre reinforced composites has the highest range of MOE values of 4.02 GPa to 5.66 GPa at 90/10 and 70/30 respectively; for wood filler composites, MOE ranged from 3.93GPa to 4.35GPa at 90/10 and 50/50 respectively; and for the yarn filler composites' MOE ranged from 3.96GPa to 4.33GPa at 90/10 and 50/50 respectively. The composites exhibit same behaviour for the MOE and MOR test. The rattan performs best with MOR values of $1.28 \mathrm{MPa}$ to $1.38 \mathrm{MPa}$ at $90 / 10$ and $50 / 50$ respectively; wood fibre ranges from 1.22 $\mathrm{MPa}$ to $1.24 \mathrm{MPa}$ at $90 / 10$ and 70/30 respectively; and yarn fibre ranges from 1.21 MPa to $1.23 \mathrm{MPa}$ respectively at $60 / 40$ and 50/50. The results compared well with standard value as reported in [15].

Table 7. Results of MOE and MOR.

\begin{tabular}{ccccccc}
\hline $\begin{array}{c}\text { Sample } \\
\text { POP/Fibre }\end{array}$ & $\begin{array}{c}{ }^{3} \text { MOEPWF } \\
\text { (GPa) }\end{array}$ & $\begin{array}{c}{ }^{3} \text { MOEPRF } \\
\text { (GPa) }\end{array}$ & $\begin{array}{c}{ }^{3} \text { MOEPYF } \\
\text { (GPa) }\end{array}$ & $\begin{array}{c}{ }^{3} \text { MORPWF } \\
\text { (MPa) }\end{array}$ & $\begin{array}{c}{ }^{3} \text { MORPRF } \\
\text { (MPa) }\end{array}$ & $\begin{array}{c}{ }^{\mathbf{M} O R P Y F} \\
\text { (MPa) }\end{array}$ \\
\hline $\mathbf{1 0 0 / 0}$ & 3.21 & 3.21 & 3.21 & 1.21 & 1.21 & 1.21 \\
$\mathbf{9 0 / 1 0}$ & 3.93 & 4.02 & 3.96 & 1.22 & 1.28 & 1.22 \\
$\mathbf{8 0 / 2 0}$ & 4.15 & 4.52 & 4.17 & 1.22 & 1.30 & 1.22 \\
$\mathbf{7 0 / 3 0}$ & 4.28 & 5.66 & 4.20 & 1.24 & 1.31 & 1.23 \\
$\mathbf{6 0 / 4 0}$ & 4.30 & 5.17 & 4.30 & 1.23 & 1.38 & 1.21 \\
$\mathbf{5 0 / 5 0}$ & 4.35 & 5.10 & 4.33 & 1.23 & 1.38 & 1.23 \\
\hline
\end{tabular}

$\mathrm{MOE}_{\mathrm{PWF}}=\mathrm{MOE}$ of POP-Wood fibre composite, MOE $\mathrm{PRF}=$ MOE of POP-Rattan fibre composite, MOE $_{P Y F}=$ MOE of POP-Yarn fibre composite, MOR $_{\mathrm{PWF}}=$ MOR of POP-Wood fibre composite, $\mathrm{MOR}_{\mathrm{PRF}}=\mathrm{MOR}$ of POP-Rattan fibre composite, $\mathrm{MOR}_{\mathrm{PYF}}=$ MOR of POP-Yarn fibre composite, ${ }^{3}$ Average of three values. 


\section{CONCLUSIONS}

Fibre-POP composites was produced from wood (Alzibia zygia), rattan (Laccosperma secundiflorum), and yarn. The composites were tested for strength and physical properties. The results derived implied that:

- The mechanical properties of all reinforced composite in terms of modulus of rupture (MOR) and modulus of elasticity (MOE) increased with increase fibre contents. However, rattan fibre reinforced composites have the highest value (MOE: 5.66 GPa and MOR: 1.38 MPa respectively at 70/30 and 50/50) meaning that bending strength of rattan reinforced composite is high. Generally, the use of fibre to reinforce Plaster of Paris considerably increased the strength properties of the material.

- The WA and TS properties increased as the fibre contents increased, this implies the composites produced will be more suitable for the internal applications such as ceiling boards.

- The fibre reinforced composites had no significant effect on the surface of the samples produced, as no new shrinkage was formed that may relate to the presence of the fibres in the composites.

\section{REFERENCES}

[1] Migneault, S., Koubaa, A., Erchiqui, F., Chaala, A., Englund, K., Wolcott, M.P., Effects of processing method band fiber size on the structure and properties of wood-plastic composites, Agricultural and Biological Engineering, vol. 40, 2009, p. 80-85.

[2] Ajayi, B., Properties of maize-stalk-based cement bonded composite, Forest Product Journal, vol. 56, no. 6, 2006, p. 51-56.

[3] Adewumi, I., Municipal solid wastes Management: The need for a paradigm shift, Ife Environmentalist, Nigerian Society of Environmental Management, Ife, 2004, p. 1-2.

[4] Omoniyi, T.E., Alabi, O.J., Performance evaluation of a single screw extruder `for the production of WPC, Forestry Association of Nigeria Annual Conference Journal, 2017.

[5] Cao, Y., Goda, K., Shibata, S., Development and mechanical properties of bagasse fibre reinforced composites,Advanced Composite Materials, vol. 16, no. 4, 2007, p. 283-298.

[6] Olorunnisola, A.O., Agrawal, S.P., Effect of $\mathrm{NaOH}$ concentration and fibre content on the physic mechanical properties of cement bonded rattan fibre composite, International Journal of Forest Products, vol. 17, 2015, p 192198.

[7] Omoniyi, T.E., Potential of oil palm (Elais guineensis) Empty fruit bunch fibre cement composites for building applications, Agri Engineering Journal, vol. 1, 2019, p. 153-163.

[8] Agopyan, V., Vegetable fibre reinforced building materials - development in Brazil and other Latin american countries in Swamy, Concrete Technology and Design, vol. 5, 1988, p. $208-242$.

[9] Lai, C.Y., Sapuan, S.M., Ahmad, M., Yahya, N., Dahlan, K.Z.H.M., Mechanical and electrical properties of coconut coir fibre-reinforced polypropylene composites, Polymer Plastic Technology Engineering, vol. 44, 2005, p. 619-632.

[10] Arib, M.N., Sapaun, S.M., Hamdan, M.A.M.M., Paridah, M.T., Zaman, H.M.D.K., Literature review of pineapple fibre reinforced polymer composites, Polymer Polymer Composites, vol. 12, no. 4, 2004, p. 341-348.

[11] http://www.worldagroforestry.org/sites/treedbs/treedatabases.asp (20.03.2020).

[12] American Society for Testing and Materials. Standard specification for fibre cement roofing shingles, shakes, ASTM International; American Society for Testing and Materials: West Conshohocken, PA, USA, 2012.

[13] Bledzki, A.K., Reihman S., Gassan J., Thermoplastics reinforced with wood fillers, A literature review, Polymer Plastic Technology Engineering, vol. 37, 1998, p. 451-468.

[14] Stark, N.E, Rowland, R.E., Effects of wood fiber characteristics on mechanical properties of wood/propylene composites, Wood and Fibre Science: Journal of the Society of Wood Science and Technology, vol. 35, no. 2, 2003, p.167-174.

[15] Wood Handbook, Wood as an engineering material, Book of the forest products laboratory, United State Department of Agriculture Forest Service, Madinson, Winconsin, 2010, p 12-33. 